\title{
Desnaturalizando la noción de frontera en el contexto migratorio
}

\author{
Denaturalizing the notion of \\ border in the migration context \\ Juan Carlos Velasco \\ Instituto de Filosofía del CSIC, Madrid \\ jc.velasco@csic.es
}

Orcid: 0000-0002-5346-4429 DOI: http://dx.doi.org/10.15366/bp.2020.23.001

Bajo Palabra. II Época. No23. Pgs: 23-48 
Este artículo se ha elaborado en el marco del proyecto "Fronteras, democracia y justicia global” (PGC2018-093656-B-I00), financiado por el Plan Estatal de I+D+i y del que el autor es Investigador Principal. Son muy de agradecer los valiosos comentarios de Isabel Turégano, MariaCaterina La Barbera, Francisco Blanco y Jesús Casquete a versiones previas de este texto.

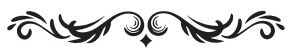

Resumen

«Frontera» $\mathrm{y}$ "muro» son utilizados a veces como términos intercambiables, aunque en realidad sus significados divergen: el primero tiene por objeto regular los tránsitos y los intercambios, por lo que, a diferencia del muro, no es en sí mismo un dispositivo obstructivo. En el contexto de las actuales políticas restrictivas en materia migratoria, resulta crucial desnaturalizar la retórica hegemónica acerca de la necesidad de fortificar las fronteras, mostrando su ineficacia, sus costes y su carácter violento. En este artículo se formula la propuesta de «fronteras abiertas» con el objetivo de, por un lado, superar la visión un tanto quimérica de un «mundo sin fronteras» $y$, por otro, establecer las bases para un régimen migratorio solidario que respete los valores básicos de las sociedades democráticas.

Palabras clave: Frontera, muro, politica migratoria, nacionalpopulismo, fronteras abiertas

\section{Abstract}

«Border» and «wall» are sometimes used as interchangeable terms, although in fact their meanings diverge. The former is intended to regulate transits and all kinds of exchanges, so, unlike the wall, it is not in itself an obstructive device. In the context of current restrictive migration politics, it is crucial to denaturalize the hegemonic rhetoric about the need to fortify the borders, showing its ineffectiveness, costs and violent character. This article outlines the approach of «open borders» in order to overcome the somewhat chimerical vision of a «borderless world» and to lay the foundations for solidarity-based migration policies that respect the basic values of democratic societies.

Keywords: Border, wall, migration policy, national populism, open borders 
L a proliferación de muros y de todo tipo de barreras a lo largo del planeta en las últimas décadas ha reabierto el debate nunca solventado acerca de la legitimidad de los Estados para cerrar o abrir las fronteras o, dicho de otro modo, acerca de si a los Estados les asiste el derecho exclusivo de controlar el acceso de extranjeros a su propio territorio o si se trata de una decisión que ha de ser justificada ante todos los potenciales afectados, sean miembros o no de la particular comunidad política en cuestión (Abizadeh 2008; Brezger 2018). La doctrina jurídico-política dominante coincide en que el control de las fronteras es una potestad soberana de los Estados, que estarían habilitados para determinar sus propios límites y establecer los criterios de pertenencia. En este sentido, se suele argumentar que, con el fin de mantener su bienestar y su propia identidad, algo a lo que tendría derecho todo pueblo constituido en Estado, las sociedades están facultadas a limitar la inmigración (Walzer 1993: 44-74; Miller 2005 y 2016). La política de recepción de inmigrantes estaría, pues, subordinada a los particulares intereses de cada sociedad. Sin embargo, esta extendida posición no representa la última palabra. Hace ya tiempo que los Estados no pueden ignorar sin más la dificultad que supone hacer compatible la facultad de todo país soberano de proteger sus fronteras y el deber indeclinable de respetar los derechos humanos. Los individuos están protegidos por ser personas, no por la nacionalidad que posean, lo que limita la autonomía de los gobiernos, que se ven confrontados así con el reto de proteger fronteras sin desproteger personas.

Más allá de que los afanes por cerrar las fronteras no sean más que una mera ilusión y una propuesta desmentida a diario por la realidad de la migración irregular masiva, numerosos estudiosos han destacado el problemático estatus normativo de unos límites territoriales que no sólo son históricamente contingentes, sino que con frecuencia son el resultado de graves injusticias y arbitrariedades, tales como conquistas, colonizaciones, cesiones sin consentimiento o compras ilegales de territorios (Foucher 2012). Si ya su origen puede ser puesto en cuestión, igualmente lo pueden ser algunas de las funciones estructurales que en la práctica se asignan a las fronteras, entre las que sobresale, aunque pocas veces sea explicitada, la de marcar oportunidades espacialmente diferenciadas para las personas (Ypi 2008: 395): un modo de consagrar las profundas desigualdades económicas existentes entre los Estados y, en definitiva, de dar carta de naturaleza a injusticias globales (Velasco 
2020). ${ }^{1}$ Estas formas de inequidad se perpetúan por la falta de cauces legales para poder migrar de manera razonable.

En este contexto, la obsesión por la seguridad, la estabilidad y el mantenimiento del statu quo a nivel global resulta completamente insoportable para quienes se encuentran en situaciones de clara desventaja. El acceso equitativo a los recursos de la Tierra y a las innovaciones humanas no es una simple opción, es un imperativo en el que está comprometida la supervivencia de la especie. La configuración de modelos políticos, sociales y económicos más inclusivos y equitativos únicamente será factible a escala global si se modifica sustancialmente el papel atribuido a las fronteras territoriales. Con el fin de ofrecer una alternativa, en este artículo se argumentará a favor de pasar de un modelo que hace de las fronteras muros supuestamente infranqueables a otro que las conciba como lugares de tránsito regulado. Tras la experiencia adquirida con la erección de miles de kilómetros de muro, es tiempo ya de reflexionar por fin sobre opciones que difieran de la disuasión por el terror y el blindaje de fronteras, la única que parece estar ahora sobre la mesa, y pensar en soluciones que sean compatibles con valores democráticos tan básicos como la solidaridad y la justicia social.

\section{Fronteras y discurso nacionalpopulista}

Hasta haCe no tANTO se podía pensar, quizás ingenuamente, que, con los procesos de globalización en marcha, las fronteras políticas estarían condenadas a la irrelevancia. ${ }^{2}$ Cuando en 1989 cayó el Muro de Berlín muchos entendieron que esa posibilidad estaba más cerca de convertirse en realidad. El optimismo cosmopolita que sobrevino al final de la Guerra Fría, aunque fuese de modo efímero, dio alas a una retórica idílica en torno a la emergencia de «un mundo sin fronteras». ${ }^{3}$

\footnotetext{
${ }^{1}$ No es por casualidad que "donde vemos a países contiguos (ya sea por tierra o agua) con grandes diferencias de ingresos, allí encontramos los lugares con las mayores barreras a la migración” (Milanovic 2017: 168-169). Por poner tan sólo un ejemplo, el territorio fronterizo hispano-marroquí está marcado por una enorme desigualdad: el nivel de renta espańol multiplica por nueve al marroquí, una brecha tanto o más abultada que la existente entre México y EE.UU. Existe, sin duda, una poderosa razón para proceder así: "En términos monetarios, la ciudadanía de los países ricos es valiosa. Se están construyendo muros físicos entre jurisdicciones, en parte porque existe un enorme muro financiero entre ser y no ser ciudadano de un país rico" (Milanovic 2017: 261).

2 Según Risse (2012: 3), la globalización supone la puesta en marcha de "procesos que erosionan la importancia social, política y económica de las fronteras nacionales”. Para Habermas (2000: 91), el significado del término está asociado, en gran medida, al progresivo desleimiento de las fronteras: "la expresión «globalización" evoca la imagen de ríos a punto de desbordarse que se llevan por delante los controles fronterizos”.

3 Tras el colapso del bloque soviético y de la bipolaridad geopolítica, la última década del siglo XX fue un período relativamente optimista en cuanto a las posibilidades de intensificar la cooperación internacional para afrontar los problemas globales (Vallet y David 2012: 6), al menos en contraste con la desolación posterior que supuso
} 
No parece, sin embargo, que desde entonces la historia haya transcurrido por esos risueños derroteros, pues lo cierto es que "los procesos globalizadores de los últimos veinte años han llevado, no a la disminución de las fronteras sino a su proliferación" (Mezzadra y Neilson 2017: 84).

El historiador David Frye (2019: 290-291), quien ha estudiado en profundidad la construcción de muros en conexión con los grandes procesos civilizatorios, llega a la conclusión de que en estos primeros años del nuevo milenio la humanidad ha entrado en la Segunda Era de las Murallas. Desde una perspectiva histórica, los recientes cambios en este terreno tienen escasos precedentes desde los tiempos de los grandes imperios de la Antigüedad. Desde el desmantelamiento del Telón de Acero, y apenas han pasado treinta años, se han trazado casi $30.000 \mathrm{~km}$ de nuevas fronteras como consecuencia del establecimiento de nuevos Estados: unos $12.000 \mathrm{~km}$ en Europa y más de $15.000 \mathrm{~km}$ en Asia Central. Tres cuartas partes de los actuales muros se erigieron después del año 2000. Desde entonces se ha hecho evidente que "la frontera ha pasado a ocupar el centro de la geopolítica contemporánea" (Tertrais y Papin 2018: 12).

Las fronteras no sólo han proliferado, sino que además se han fortificado con el fin de intentar detener los flujos de personas, algo que como tal no forma parte intrínseca de su sentido primordial, que no es otro que el de simple demarcación territorial, esto es, una línea de deslinde entre comunidades políticas. Aunque a veces no sean más que líneas en la arena, el trazado físico de las fronteras políticas sirve para señalar el territorio en donde se hace valer la jurisdicción de cada Estado. Su presencia se delata mediante banderas, colores en los mapas y rótulos en distintas lenguas. Las fronteras transforman así un espacio geográfico en un espacio político, delimitando los territorios con el fin de estabilizar un determinado orden del mundo (Balibar 2005: 77-86).

La comprensión de las fronteras como un dispositivo esencialmente obstructivo, tal como se compendia en la imagen de los muros, representa tan sólo una simplificación interesada que, sin embargo, se ha difundido con éxito. Fronteras y muros no son dos nombres de un solo concepto. Las funciones atribuidas a unas y a otros son nítidamente diferenciables en lo referente a la circulación de personas y bienes: la función primaria de las fronteras, a diferencia de los muros, no es impedir los intercambios, sino la de regular el tránsito (esta idea se desarrollará con mayor detalle en el apartado 4). Lo que se requiere entonces es explicar cómo se ha producido esta sustancial mutación del sentido atribuido a las fronteras.

los atentados del 11-S y, sobre todo, de la gran crisis económica que arrancó tras el crash de 2008 . Tales acontecimientos transformaron la confianza en pesimismo y desafección, a la vez que azuzaron un repliegue unilateralista en numerosos Estados. 
Cabe ofrecer alguna hipótesis que permita esclarecer el entramado ideológico, socio-económico y cultural que subyace a la mencionada mutación. Sin menospreciar las explicaciones materialistas que inciden en los componentes infraestructurales, una bastante verosímil apuntaría al papel de los discursos que anteceden a la implantación de determinadas políticas, sobre todo de aquellos discursos dirigidos a conformar prejuicios y contribuir a la artificial fabricación de enemigos. La definición de la realidad mediante un lenguaje manipulado forma parte de la lucha por la hegemonía tanto en el plano político como en el cultural. Este proceder también se da en el caso de las políticas migratorias, donde se observa que la implantación de medidas severas ha estado precedida por la difusión de un discurso manifiestamente antiinmigratorio. En una primera fase, se trataba de propagar un lenguaje, una semántica y, en definitiva, un nuevo marco ideológico y conceptual; sólo más adelante, se desvela que el objetivo último no era otro que el de construir un cuadro mental políticamente explosivo que justifique la implementación de regulaciones migratorias rigurosas e incluso virulentamente hostiles (Bauman 2016: 11-12).

Una machacona labor de zapa realizada en los medios de comunicación - tanto en los tradicionales como en las cada vez más decisivas redes sociales- abona el terreno donde hacer valer un nuevo marco conceptual (Lakoff 2007). En lo referente a las migraciones, en los últimos ańos se ha ido consolidando un marco discursivo con un sesgo muy preciso: "La premisa de las políticas migratorias actuales es que allí donde hay personas moviéndose entre países hay "un problema de seguridad»" (Penchaszadeh y Sferco 2019: 153). En la misma medida en que la eficiencia y, sobre todo, la seguridad ganan en aprecio social en detrimento de las libertades, las reglas de la democracia y del Estado de derecho pierden en estima frente a la tecnocracia y el autoritarismo.

Este marco securitario, que está siendo asumido velozmente por formaciones políticas de distinto tenor (y no sólo por las más radicales), suele poseer un sesgo nacionalpopulista como rasgo distintivo, que se traduce en la exaltación autárquica de los intereses nacionales y en la instigación de un discurso antiélite y anticosmopolita (Taguieff 2012; Brubaker 2017). ${ }^{4} \mathrm{Al}$ maniqueísmo social naturalizado se añaden otras tácticas igualmente tóxicas, tales como la tergiversación informativa sistemática o la construcción deliberada de conflictos. «Primero, los nuestros (los

\footnotetext{
${ }^{4}$ Si según el Cambridge Dictionary, el término "populism» se define como "ideas y actividades políticas que están destinadas a obtener el apoyo de la gente corriente ofreciéndoles lo que quieren", el sentido del término "nacionalpopulismo" puede colegirse de la restricción del conjunto de la "gente corriente" al conformado exclusivamente por los integrantes de una determinada comunidad política nacional. Con estas bases, se comprende que entre los principales tópicos la retórica nacionalpopulista se encuentre la animadversión hacia la «élite liberal y cosmopolita", a la que se tilda de desarraigada, y el rechazo de "las virtudes de un orden internacional liberal, la disolución de las fronteras y la búsqueda de soluciones conjuntas a problemas compartidos” (Wind 2019: 19).
} 
nacionales)» o «Mano dura con el extranjero» son algunas de las muchas consignas tribalistas difundidas por los partidarios de esta tendencia política en ascenso con el fin de ahondar la distinción entre «nosotros» y «ellos» y exacerbar la polarización social (Wind 2019). El objetivo no es sino hacer eclosionar un nativismo reaccionario armado de un lenguaje belicoso que confronte un ellos amenazante con un nosotros amenazado. En este marco, eventualmente condimentado de un matiz religioso fundamentalista (Zamora 2019), se convierte también en moneda común un tipo de demagogia en la que no cabe consideración alguna en aprecio de las relevantes aportaciones que los inmigrantes hacen al bienestar general de las sociedades receptoras ya sea en clave demográfica, económica o cultural. Los migrantes no son sino el chivo expiatorio con el que calmar un malestar más de fondo.

Los nacionalpopulismos, especialmente en los países más prósperos, azuzan sin disimulos la propagación del chovinismo del bienestar. ${ }^{5}$ En el modelo social que propugnan se mantiene en cierto modo el ideal de solidaridad, materializada en las protecciones prestadas por el Estado y configurada con un alcance estrictamente nacional (Latour 2019: 12), esto es, una solidaridad reservada en exclusiva a los nativos. Frente a cualquier atisbo de hospitalidad cosmopolita, se insiste en el carácter necesariamente topológico o situado de los bienes sociales, que supuestamente impide que puedan ser compartidos con quienes vienen de fuera (sin reparar en los réditos de su presencia, esto es, sin darles ni tan siquiera la oportunidad de demostrar que con su esfuerzo, cualificación e impuestos pueden contribuir significativamente al bienestar del país anfitrión). Garantizar este tipo de sistema social cerrado se convierte en un objetivo que legitima el rechazo del extranjero y, con ello, la puesta en marcha de políticas migratorias restrictivas.

Una vez que se adopta este nuevo marco ideológico, resulta fácil justificar el incremento del peso asignado a la función discriminatoria de las fronteras, que se convierten en líneas del territorio donde tiene lugar la clasificación entre flujos deseables e indeseables, entre bienes y personas, a través de dispositivos físicos o administrativos. Los esfuerzos se dirigen entonces a intentar contener los flujos migratorios no deseados sin reparar en medios ni en principios. La polarización inducida conduce a la violencia simbólica y, en último término, a la violencia física. Así, como solución mágica se propone el cierre de fronteras y como supuesta panacea, la erección de más muros y demás tipos de obstáculos. Poco importa que levantarlos resulte un esfuerzo bastante poco eficaz para lograr el objetivo expresamente señalado, aunque sea rentable, eso sí, para quienes se lucran con su construcción,

\footnotetext{
5 La noción de chovinismo del bienestar fue acuñada por Jürgen Habermas (1998: 636-643) para dar cuenta de la extendida resistencia de las sociedades más desarrolladas a compartir las oportunidades y los derechos sociales que disfrutan con personas procedentes de países menos aventajados.
} 
mantenimiento y vigilancia (Rodier 2013), todo un conglomerado de pingües negocios que florece a la sombra del Estado (Andersson 2014). Y al parecer, tampoco importa mucho que este proceder sea profundamente insolidario con los desheredados del planeta, esa parte no tan nimia de la humanidad.

Las fronteras, fortificadas con la vana justificación de garantizar la integridad socio-cultural del país o de impedir nuevas formas de delincuencia, apenas pueden ocultar su función de barreras frente a quienes huyen de la miseria, las guerras, las tiranías, las catástrofes naturales y otras desgracias. Con estos mimbres, que no reparan en la construcción del enemigo, se construye un discurso ideológico con el que ofrecer a los ciudadanos un culpable de todos sus males: los inmigrantes y los parias. Si se mira con detalle, no se trata tanto de xenofobia, como de aporofobia: no se rechaza al extranjero en general, sino al extranjero pobre (Cortina 2017). ${ }^{6}$

\title{
2. Fronteras fortificadas, un dispositivo escenográfico
}

\begin{abstract}
"Los cierres de fronteras son evidentemente una expresión desesperada de soberanía. Nos sentimos de vuelta en la época de la soberanía. El soberano es quien decide sobre el estado de excepción. Es soberano quien cierra fronteras. Pero eso es una huera exhibición de soberanía que no sirve de nada"
\end{abstract}

(Han 2020).

Hace ya TIEMPo QUe De los Discursos se ha pasado a los hechos. Aunque aún no es lo más habitual, son muchas las fronteras terrestres que han adquirido entidad física mediante la erección de ciertos elementos de contención, que pueden variar desde una simple alambrada hasta una auténtica muralla: "Concertinas, detectores de movimientos, vallas electrificadas y bloques de hormigón asoman por el horizonte y se extienden por el paisaje a lo largo de cientos de kilómetros" (Frye 2019: 290). Entre los escenarios más conocidos que se han visto modificados radicalmente en los últimos años se pueden citar los siguientes: los que se extienden entre Estados Unidos y México, España y Marruecos, Israel y Palestina, India y Pakistán, India y Bangladesh, Georgia y Osetia del Sur, Corea del Norte y del Sur, Bulgaria y Tur-

\footnotetext{
${ }^{6}$ Inmigrantes y parias son, en realidad, categorías cada vez más confluyentes, en la medida en que gran parte de los migrantes contemporáneos se han convertido en los últimos de la fila de un orden global: no son más que vagabundos en busca de trabajo y cuyo lugar propio siempre se encuentra en otra parte. No hay que olvidar que, en el fondo, "la raza más detestada de todas, las más perseguida y discriminada, es la raza de los pobres" (Savater 2000: 9).
} 
quía, Botswana y Zimbabwe, Malasia y Tailandia o Marruecos y el Sáhara Occidental (Tertrais y Papin 2018).

Por norma general, y a diferencia de la Gran Muralla o del muro de Adriano, durante las últimas décadas los elementos de contención se han ido erigiendo sobre el terreno fronterizo con el propósito no tanto de detener el avance de ejércitos enemigos como de impedir el tránsito de personas desarmadas. Pervive, eso sí, la necesidad de resguardar el territorio de los «bárbaros», aunque ahora se les asigne el rostro de «terroristas», «refugiados» o «migrantes sin papeles». Con este preciso objetivo se movilizan patrullas fronterizas, vuelos de observación, drones de última generación equipados con cámaras, sensores de calor y movimiento, así como todo tipo de sofisticadas tecnologías. Asimismo, se intensifican y se refinan las medidas de control en los aeropuertos, se implica a las compañías aéreas en la comprobación de la idoneidad de los pasajeros para acceder a determinados destinos, se generaliza la exigencia de dotarse de pasaportes electrónicos o se desplazan preventivamente esos controles a los lugares de origen. Algunos países incluso externalizan el control migratorio, en una suerte de subcontratación. ${ }^{7}$ La frontera se vuelve así un dispositivo omnipresente: mediante una gran diversidad de prácticas (inspecciones aleatorias, leyes de inmigración, visados, control de divisas, políticas de interceptación marítima, etc.) y artefactos (algunos de índole digital y biométrica), la frontera acaba inscribiéndose "en los cuerpos de los migrantes y llevando aún más lejos la desterritorialización de las fronteras" (Mezzadra y Neilson 2017: 204). ${ }^{8}$

A pesar de las ingentes inversiones ejecutadas, ni los muros ni las alambradas ni las demás medidas mencionadas logran impedir que los flujos migratorios continúen. Los incontables cruces de fronteras o las estancias ilegales en Estados Unidos o en la Unión Europea que se registran cada año no son sino fehacientes muestras de la ineficacia de tales políticas: "Desde una perspectiva global, lo único que han hecho las verjas ha sido desplazar los problemas hacia otro sitio" (Frye 2019: 300). Se dificultan las travesías, ciertamente, y, de hecho, algunas verjas están regadas con la sangre de miles refugiados e inmigrantes, pero no llegan a ser realmente insalvables ni disuasorias. No obstante, los muros y otros tipos de obstáculos, al igual que

\footnotetext{
7 En las últimas décadas, numerosos países del Primer Mundo han ido trasladando las fronteras administrativas fuera de su propio jurisdicción: "Con la externalización de las fronteras, otros países, especialmente los de tránsito (México y Turquía, Marruecos y Libia, por ejemplo), se encargan de establecer las políticas migratorias y fronterizas que evitan el cruce al destino final de las personas que han encontrado en la movilidad humana la única forma de sobrevivencia" (Rodríguez Ortiz 2020: 24). Esta estrategia contribuye, sin duda, a que la gestión de la migración sea vista como un tema de seguridad global más que como una cuestión en clave sociodemográfica.

8 Procedimientos similares se aplican también en el caso de los solicitantes de asilo. Como ha mostrado FitzGerald (2019), los gobiernos de las democracias más prósperas del planeta han desarrollado técnicas cada vez más elaboradas de "control remoto" (extra-territorialización) y de micro-distinciones en la línea fronteriza (hiper-territorialización) para mantener a dichos solicitantes lejos de los espacios donde puedan pedir refugio.
} 
en general las políticas migratorias restrictivas, provocan desplazamientos de las rutas de llegada, alargando el trayecto y aumentado los riesgos, además de inducir dañinos efectos colaterales: los migrantes se ven impelidos a utilizar medios ilegales tanto para ingresar en el país deseado como para permanecer en su interior, de modo que la inmigración irregular aumenta aún más (Pécoud y Guchteneire 2006: 81). ${ }^{9}$ No hay empero medidas de control fronterizo que sirvan para contener los sueños de la gente e impedir que las personas entren en un país y, menos aún, para detener a quienes espoleados por la desesperación quieren salir de su propio país. La pregunta por su sentido se hace entonces inevitable.

La mayoría de los muros erigidos en el siglo XXI han de interpretarse como respuestas fallidas a la creciente obsolescencia de los Estados soberanos en un mundo en globalización: no son expresión de soberanía ni de poder, sino más bien de impotencia. Pese al declive del Estado-nación en una constelación postwestfaliana ${ }^{10}$ (o, quizás más bien, precisamente debido a ello, véase Sassen 2001), la perspectiva alicorta propia de esta forma aún hegemónica de organización política — cuyas coordenadas de referencia son la soberanía, el territorio y la ciudadanía - determina completamente el tipo de políticas migratorias, no sólo su diseńo, sino también su implementación. En pocos otros terrenos de lo social la lógica particularista desplegada por los Estados territoriales soberanos resulta tan implacable: "Da igual que sea grande o pequeño, todo Estado se acaba reduciendo siempre a la misma idea básica: la soberanía territorial, es decir, la capacidad de actuar dentro de las propias fronteras tal y como desean los habitantes de esas fronteras y no al dictado de terceros" (Bauman 2017: 66). En un mundo interconectado e interdependiente, en el que los distintos pueblos han entretejido una maraña de complejas relaciones, el propósito de recuperar la plena soberanía se revela como una quimera: ya nadie es, en un sentido mínimamente estricto, señor efectivo de su tierra. La deslocalización de empresas o los flujos internacionales de capitales, por poner tan sólo dos ejemplos, desmienten cualquier alarde de soberanía en la esfera económica.

Es un hecho observable que "el muro se ha convertido en una nueva norma en las relaciones internacionales" y que incluso "las democracias se han apropiado de

\footnotetext{
9 Un efecto realmente contrastable del endurecimiento del control fronterizo no es el cese de la irregularidad migratoria, sino el suministro al sistema económico de mano de obra barata y sumisa (De Genova 2002). El reforzamiento de las fronteras responde a un proceso intencional que no persigue tanto ordenar las migraciones como optimizar los mecanismos de explotación de los trabajadores trasnacionales.

${ }^{10}$ En el actual momento postwestfaliano de la geopolítica, en el que la capacidad de mando y regulación de los Estados está disminuyendo sensiblemente, "hay más bien una dispersión de elementos de soberanía política que una transferencia in toto de la misma” (Brown 2015: 97) hacia instancias supra- o infranacionales. Así, aunque con salvedades, pues acuerdos e instituciones internacionales imponen algunos límites al comportamiento de los Estados, el principio de no injerencia en los asuntos internos aún conserva cierta vigencia y las fronteras estatales siguen mereciendo la máxima protección internacional.
} 
este instrumento como si fuera una herramienta clásica de la política exterior y de defensa" (Vallet 2019). No resulta tan evidente, sin embargo, la lógica subyacente a la multiplicación de muros: las justificaciones explícitas pocas veces casan con los auténticos objetivos. Pese a la apariencia contraria, los muros son expresivos signos de la manifiesta incapacidad de los Estados para gobernar las dinámicas asimétricas desencadenadas por los procesos de globalización neoliberal, con brechas de desigualdad cada vez más anchas. Aunque presentados como genuinas respuestas políticas, tienen mucho de espectáculo, de atrezo teatral montado ante poblaciones cada vez más atemorizadas por las precarias perspectivas de futuro.

Los muros se han convertido en iconos generadores de cohesión en una doble dirección: gracias a los muros, quienes están dentro fantasean con compartir una uniformidad sobre la que construir una comunidad cerrada, mientras que, hacia fuera, la imagen de fortaleza que irradian los muros cohesionan a quienes esperan agazapados en la frontera para poderla cruzar. Como iconos de la exclusión de los otros, los muros se izan con la esperanza de tranquilizar a los propios con la falsa imagen de un orden reconfortante. Dicho en lenguaje casi poético: "Encastillados en su centro, consolidan las fronteras como límites de sus dominios, alzando murallas y cerrando puertas. [ ] fortificados dentro de su país" (Sampedro 1991: 17). En realidad, todo este incesante trajín está al servicio de un artificio escenográfico: los muros no tienen más valor que el de un exorcismo simbólico del miedo colectivo. Restaurar la visibilidad de las fronteras pretende calmar la ansiedad, a veces imaginada, ante el clamor y la furia del mundo (Foucher 2016: 8).

Más allá de estos efectos performativos, los muros son instrumentos poco o nada operativos para solventar los problemas de fondo para los que expresamente se erigen. Pero dado que construirlos sigue siendo una forma poderosa de teatralidad política, constituyen una obsesión para quienes se nutren electoralmente de ese miedo irracional, por infundado, a que los inmigrantes "nos invadan", el miedo que, como siempre, cortocircuita toda reflexión. Por todo ello, y aunque la pulsión obsesiva por los muros fuera previa, no es casual que Donald Trump — que logró ascender al poder gracias, en no poca medida, a la reiterada promesa de blindar la frontera sur de Estados Unidos y alejar a los migrantes latinoamericanos - se haya convertido en un faro inspirador para los partidos más reaccionarios y populistas de Europa y de gran parte de América.

Las políticas dirigidas a impermeabilizar las fronteras tan sólo pueden esperar el refrendo de la opinión pública si previamente se ha logrado que calen mensajes que, además de instilar considerables dosis de desprecio por los extranjeros, consolidan la representación de las fronteras como un hecho prepolítico incontrovertible, como marco natural de todo Estado. Se precisa que su carácter intrínsecamente artificial 
quede camuflado, como tantos objetos de la construcción social de la realidad, por un intenso proceso de naturalización (que, tras rutinarias repeticiones, devienen en opiniones acríticamente asumidas). En no poca medida esto ya se ha logrado: la entidad de las fronteras, como la de los mismos Estados, se impone a la conciencia de los individuos y aparecen ante sus ojos como realidades dadas e inamovibles (Boudou 2018). Es más, las fronteras son presentadas con frecuencia como un fenómeno al margen de la política, sobre el que no cabe hacerse preguntas ni, por tanto, pensar alternativas, igual que sucede, por ejemplo, ante un terremoto o un tsunami. Si las fronteras fueran un fenómeno natural de los que se acaban de citar, entonces habrían surgido al margen de la voluntad de los hombres. Pero sabemos que eso es una ficción insostenible y que son más bien un producto socio-histórico y que, por tanto, esos símiles no son pertinentes. Sería mucho más ajustado asemejar las fronteras a la sismicidad inducida por el uso de las técnicas de fracking: un fenómeno catastrófico en absoluto natural, sino provocado por la intervención humana. Como de las secuelas producidas por tales fracturaciones, también de los nocivos efectos generados por las fronteras cabe pedir cuentas, pues no dejan de ser consecuencia de actos humanos (Shklar 2010). Y esos actos no afectan a todo el mundo por igual.

\section{Sobre la necesidad de alternativas en materia de política migratoria}

Es CIERTO QUE, ante las obvias dificultades para mantener un país enteramente clausurado, con frecuencia se practica un juego selectivo de apertura/cierre, pero ello no impide afirmar que ya la propia pretensión de mantener blindadas las fronteras implica apostar abiertamente por modelos inicuos de exclusión y contención. Además de violar el ius communicationis entre los humanos, las restricciones migratorias y el aumento de las medidas para dificultar el tránsito fronterizo no son neutrales en términos de equidad: operan como dispositivos coercitivos que constriñen en gran medida las oportunidades de las personas y genera importantes desigualdades distributivas. En la medida en que tales políticas chocan con los derechos humanos y los principios básicos de justicia configuran una situación injustificable en términos normativos. Para ponerle algún remedio se precisan planteamientos alternativos que proporcionen una base para la implementación de políticas que vayan más allá de la mera crítica del daño y la inequidad de tales restricciones, que sean capaces de imaginar un mundo con unos límites concebidos de manera más permeable (Weber 2015).

Cuando se contemplan los actuales procesos migratorios desde una perspectiva global, el escenario óptimo o ideal sería aquel en el que todas las personas pudieran 
satisfacer sus necesidades básicas en su lugar habitual de residencia y no se vieran impelidas a tener que emigrar (Risse 2012: 153), de modo que si finalmente emigran lo hagan de manera no forzada, sino por voluntad propia. Al fin y al cabo, tan básico como el derecho a poder emigrar es el derecho a no tener que emigrar y poder permanecer en el propio país (Oberman 2011). Sin embargo, la realidad de nuestro mundo se parece poco a ese escenario ideal. Son muchas, demasiadas, las personas que ni pueden atender las necesidades más primarias en su propio país y menos aún seguir dignamente sus planes de vida, ni pueden tampoco desplazarse legalmente a otro país en búsqueda de un nivel de vida decente para ellos mismos y sus familias (IOM 2019). En no pocos casos, afrontan cualquier peligro y sacrifican lo poco que tienen con tal de poder acceder al territorio de sus sueños.

Son cada vez más quienes abandonan su tierra en contra de su voluntad al verse expulsados de sus lugares de origen (Sassen 2017). No pocas veces se ven impelidos a arriesgar sus vidas a través de peligrosos desplazamientos. Esto es lo que les sucede a quienes habitan en lugares que en las últimas décadas se han desertificado, se han vuelto superficies inundables, ${ }^{11} \mathrm{o}$ bien, a quienes moran en tierras asoladas por la violencia; pero, también a quienes viven en países relativamente prósperos y ven que los trabajos para toda la vida se extinguen (a causa de la desindustrialización, de la robotización o de las deslocalizaciones), las prestaciones sociales menguan o las pensiones parecen estar en peligro. Para los perjudicados por la globalización, la migración se presenta como una vía rápida de acceso a sus posibles beneficios, que, al mismo tiempo, muchos gobiernos se empeñan en cerrar.

Sin embargo, hace tiempo que, en el ámbito internacional, el derecho a salir del propio país, el derecho a emigrar ha sido reconocido como un derecho humano. Así lo establece la Declaración Universal de Derechos Humanos (artículo 13.2) y el Pacto Internacional de Derechos Civiles y Políticos (artículo 12.2). Sin embargo, en esa misma Declaración se deja sin tutela el complementario derecho a inmigrar, sin el cual la proclamación de aquel otro derecho no son más que palabras hueras (Velasco 2016: 292-295). En este escenario contradictorio en torno a una comprensión integral del ius migrandi es donde la flexibilización del control fronterizo adquiere plena significación. Pese a las intensas disputas académicas registradas en los últimos ańos, el derecho a la

\footnotetext{
${ }^{11}$ Con el cambio climático antropogénico y las catástrofes ambientales derivadas de él, las migraciones adquieren un nuevo perfil (Campillo 2019: 54-57). A diferencia de lo que sucedía con anteriores flujos de personas, ahora ya no se trata "de migrantes en busca de mejor vida que esperan enviar dinero y algún día regresar a la familia que dejaron atrás, sino de personas que buscan simplemente sobrevivir y no tienen una casa a la cual regresar" (Sassen 2017: 13).
} 
inmigración sigue sin figurar en ninguna agenda política. Y ésa es precisamente la batalla que falta aún por dar. Para ello, al menos en un primer momento, no es mala idea dejar de lado la teoría ideal, ámbito en el que los desencuentros suelen ser rotundos.

Si se adopta una perspectiva pragmática, un buen punto de partida para el cuestionamiento de las rigurosas políticas migratorias actualmente predominantes es la comprobada ineficacia de las políticas de control de fronteras y, en particular, de construcción de muros. Es una evidencia contrastada que las políticas restrictivas no cumplen cabalmente los objetivos proclamados de limitar la migración, ajustando su volumen y composición a los intereses y necesidades de las sociedades receptoras. Entre otros motivos, los esfuerzos resultan infructuosos porque la migración está estructuralmente arraigada en las economías de la mayoría de los países, sean receptores o emisores, bien en forma de remesas, de mano de obra barata o de servicios domésticos. Las medidas de contención del acceso, y más si se reducen al sellado de las fronteras, representan una respuesta inadecuada porque entran en contradicción con poderosas dinámicas difíciles de controlar por cualquier gobierno. A esta constatación se le puede ańadir otro argumento, de carácter igualmente pragmático, que hace hincapié en el considerable ahorro que para las cuentas públicas supondría el desmantelamiento de los costosísimos sistemas de control de fronteras instalados. Estos razonamientos no logran, sin embargo, sacudir suficientemente las opiniones públicas y menos aún detener las prácticas de tantos gobiernos que se muestran convencidos de obtener mayores réditos electorales con sus bravas retóricas y sus duras políticas.

En este contexto, y con el fin de construir cartografías mentales alternativas, se hace cada vez más patente la necesidad de introducir algún elemento distorsionante en el discurso hegemónico sobre políticas migratorias. Esto es, unas herramientas disruptivas capaces de darle la vuelta al tablero de juego, algún tipo de propuesta que rompa con inercias y que haga replantear los dogmas rutinarios en torno al tema de las fronteras y a su papel a la hora de definir la estructura básica del orden global. Esta labor es imprescindible, pero se precisa igualmente otra aún más ardua: no cabe implementar nuevas políticas sin forjar previamente un amplio consenso que las avale.

Pese a las dificultades, en la esfera internacional se ha avanzado en los últimos ańos en algunos consensos mínimos acerca de cómo ofrecer un marco favorable para abordar de manera comprensiva el fenómeno migratorio. En este sentido, probablemente el paso más alentador sea el acuerdo multilateral rubricado en Marrakech en 2018 por parte de 164 países: el Pacto Mundial para una Migración Segura, Ordenada y Regular, un texto que previamente había sido convenido 
por la Asamblea General de las Naciones Unidas (ONU 2018). ${ }^{12}$ Este Pacto se articula sobre dos presupuestos básicos: el primero, la primacía de los derechos humanos en la gestión de movilidad internacional; el segundo, la consideración de la migración como un factor clave de desarrollo. El propósito principal no es otro, como expresa el propio título del Pacto, que el de establecer canales para la inmigración legal y ordenada, más concretamente: "Aumentar la disponibilidad y flexibilidad de las vías de migración regular". La identificación de este propósito es todo un acierto y completamente oportuno: es crucial en un momento en el que los gobiernos tienden cada vez más a perseguir y criminalizar no sólo la migración irregular sino incluso el auxilio prestado por particulares a los migrantes en estado de necesidad (lo que implica, por ejemplo, subvertir la legislación internacional sobre el deber de auxilio en el mar), todo ello sin ofrecer como contrapartida unos canales seguros y previsibles que permitan a la gente poder migrar. Si los países desarrollados precisan de un número cada vez mayor de mano de obra extranjera para que sus economías resulten sostenibles y paliar el envejecimiento de la población, un mínimo de sentido común exigiría que la migración no fuera obstaculizada, sino más bien encauzada. ${ }^{13}$ Como se ha señalado en los dos últimos apartados, el Pacto va sin duda a contracorriente de los vientos políticos que corren en los países más desarrollados.

El mencionado Pacto adolece, no obstante, de una grave carencia: no es vinculante jurídicamente. Los Estados pueden irlo acumulando a un amplio repertorio de acuerdos internacionales suscritos que, en realidad, no les fuerzan a cambiar sus propias políticas. Con todo, y pese a su aparente inanidad, relevantes países receptores ya se han desvinculado del Pacto. Esta renuencia indica también que, por poco valor que tengan este tipo de acuerdos, siempre pueden tornarse en referencia crítica para medir las políticas que se siguen. A nadie le gusta ver su fea cara reflejada en un espejo. No obstante, para forzar los cambios preconizados por el acuerdo sería conveniente, o más bien indispensable, disponer de un organismo supraestatal competente, que facilitara los movimientos transfronterizos y que velara por el efectivo respeto de los derechos de quienes los protagonizan, el eslabón siempre

12 El Pacto de Marrakech es el mínimo común denominador que fue posible alcanzar para plasmar en un instrumento de derecho internacional la mucho más ambiciosa Declaración de Nueva York para los Refugiados y los Migrantes. Aprobada en 2016, por la Asamblea General de Naciones Unidas, esta declaración urgía una mayor cooperación entre las naciones para abordar la migración en forma justa y eficaz.

${ }^{13}$ Este tipo de argumentos inciden en el carácter instrumental de la inmigración. Es cierto que actualmente los países más desarrollados requieren extranjeros para que trabajen en lo que los nativos no quieren trabajar, pero ¿qué ocurriría si en un momento dado los inmigrantes no fueran imprescindibles? ¿Ya no podrían inmigrar o ni siquiera merecerían quedarse donde un día nacieron? Que la inmigración no sea tan importante como mano de obra es una situación que, al fin y al cabo, puede darse en algún momento en la medida en que se expanda aún más la robotización o el trabajo deslocalizado. 
más débil. El Pacto no cuestiona ni la soberanía de los Estados ni las fronteras nacionales. Si bien es cierto que actualmente no se dan las condiciones para alcanzar un acuerdo más exigente que comprometa a todos los países, también es verdad que con pactos de este tipo sólo es posible alcanzar resultados paliativos, pero no realmente transformadores. La idea de establecer cauces regulares y seguros, que resulten además previsibles para quienes buscan migrar, es una alternativa a tener en cuenta y que no habría que desechar, pero tal como está ahora planteada carece de la fuerza impugnadora capaz de irrumpir en el debate público y crear un nuevo marco discursivo.

\section{Resignificando las fronteras}

EN EL MUNDO DE HOY no cabe prescindir de las fronteras sin más, pero dados los efectos indeseados que su permanencia genera es igualmente imprescindible aprender a convivir con ellas. Con este objetivo a la vista, es preciso reconfigurarlas en el plano teórico e indicar las condiciones necesarias para que acaben también transformándose en el plano práctico. La comprensión de las fronteras como un dispositivo esencialmente obstructivo — tal como se compendia en la imagen de los muros- representa tan sólo una percepción simplificadora. El complejo fenómeno de las fronteras admite lecturas más integradoras que no quedan atrapadas por la generalización de determinadas prácticas de contención excluyente, por muy extendidas que estas se encuentren. En apoyo de una concepción de la funcionalidad de las fronteras distinta a la hegemónica, resulta ilustrativo remitirse al tipo de reflexiones formuladas por teóricos contemporáneos tan dispares como Régis Debray (2016), Rainer Bauböck (2015) o Sandro Mezzadra y Brett Nielson (2017).

Para el primero de estos autores, la función comúnmente atribuida a la frontera está teñida de ambigüedad, pues a la vez que "inhibe la violencia, puede justificarla. Sella la paz y desencadena la guerra. Humilla y libera. Disocia y reúne" (Debray 2016: 32). Esa versatilidad no es accidental, sino constitutiva: las fronteras no son solo coordenadas de separación, sino también dispositivos interactivos que posibilitan los flujos de comunicación: separan y unen. De ahí que quienes están a uno u otro lado de un trazado fronterizo tienen esa equívoca percepción de estar a la vez lejos y cerca. De manera similar a como la piel que recubre un organismo vivo, las fronteras han desempeñado a lo largo de la historia también la misión de conectar: "la piel está lejos del telón hermético como la frontera digna de ese nombre lo está del muro. [ ] Decir de una frontera que es un colador es hacerle justicia: la frontera está ahí para filtrar" (Debray 2016: 43). Las fronteras, en realidad, no son imper- 
meables, sino porosas, de modo que a sus márgenes se generan con frecuencia sociedades y culturas transfronterizas profundamente interactivas. Con acentos propios, esta idea también es defendida por Bauböck (2015: 172): "las fronteras estatales no tienen que construirse ni como barricadas móviles ni como muros rígidos. Una tercera posibilidad es pensarlas como membranas, esto es, como estables, pero al mismo tiempo permeables".

En el marco de la actual división internacional de la mano de obra, la función primordial de las fronteras, a diferencia de los muros, no es impedir los intercambios, sino la de posibilitarlos mediante una peculiar regulación del tránsito: "las fronteras, lejos de servir simplemente para bloquear u obstruir los flujos globales, han devenido dispositivos esenciales para su articulación" (Mezzadra y Neilson 2017: 21). Según estos dos autores, esta ambigüedad funcional estaría, en realidad, inducida por la lógica del capital transnacional: los sistemas de control fronterizo constituyen instrumentos esenciales para el filtrado y la selección de la mano de obra que proporcionan los movimientos migratorios. Las fronteras serían, pues, dispositivos orientados por objetivos de explotación, desposesión y dominación. Un uso muy extendido, pero sobre el que cabría convenir en que no sería precisamente el más recomendable, al menos desde una visión anclada en los derechos humanos.

Para poder enderezar esta frecuente deriva se requiere, sin duda, un radical cambio de enfoque que propicie una actitud abiertamente cooperativa. A partir de una regulación jurídica de alcance supraestatal, sería factible afrontar de otra manera los flujos migratorios y pensar en la posibilidad no tanto de eliminar las fronteras como de mantenerlas habitualmente abiertas. De este modo, las fronteras, en lugar de separar, impulsarían más bien la comunicación y la interacción entre las distintas partes de la humanidad.

Distinguir entre fronteras y muros en virtud de su transitividad o intransitividad no sólo es clarificador, sino que resulta operativo para contraponer la función «jurisdiccional» de la frontera de la función «de contención» u «obstaculizante» del muro. Existe, no obstante, una suerte de continuidad esencial entre estos dos dispositivos, aunque sea sólo porque ambos se erigen generalmente en la línea geográfica en las que se trazan las primeras. Los dos marcan un «límite», pero solamente uno impide drásticamente la comunicación y el tránsito de un lado a otro: con los muros se dan varios pasos más en la construcción de compartimentos estancos en el espacio geopolítico. ${ }^{14}$

\footnotetext{
${ }_{14}$ Quisiera agradecer a Francisco Fernández-Jardón por llamar mi atención sobre la distinción entre transitividad e intransitividad de las fronteras.
} 


\section{Las fronteras abiertas como subversión del statu quo global}

LA PERSPECTIVA DE QUIENES SUFREN en primera persona los rigores de la desigualdad, de la violencia o del cambio climático y que se ven impelidos a migrar es una voz relevante que tiene que ser atendida en los procesos colectivos de comprensión y gestión de los movimientos migratorios. Hoy, para muchos parias de la Tierra, el sueño más profundo o, si se prefiere, la utopía más atractiva, ya no es cambiar el país en el que viven, esto es, cambiar su sistema político y su estructura económica, sino cruzar las fronteras y cambiar de país (Krastev 2017: 165-166). Al no contener representación de un régimen ideal, esta pequeña utopía ya no precisa comprometerse con un mañana glorioso que sirva de acicate: está guiada por la triste certeza de que no se puede seguir sobreviviendo sin un cambio radical de ubicación. En el fondo, la convicción que la anima no es otra que la que es preciso salir para evitar la catástrofe y la ruina. ${ }^{15}$

Sea como fuera, tras el colapso de las utopías sociales y los grandes relatos de emancipación, este nuevo tipo de revolución no se inspira en imágenes del futuro diseñadas por grandes ideólogos, sino en imágenes proporcionadas por múltiples canales de comunicación sobre la vida al otro lado de la frontera. Los nuevos medios hacen mucho más perceptibles las desigualdades globales, no sólo las referentes a la economía, sino también a la ecología. En un mundo convertido en aldea global, la gente compara sus vidas no con la de sus vecinos, sino con la de los habitantes de los países más ricos del planeta o con quienes disfrutan de un ecosistema mucho más propicio, dos situaciones, que, aunque dispares, no es infrecuente que vayan de la mano. A diferencia de lo que sucedía en otras épocas, sus sueños de una vida mejor en otro país se topan cada vez más con unas fronteras cerradas a cal y canto. Hasta tal punto se ha naturalizado no sólo el control de las fronteras sino incluso el levantamiento de muros y de todo tipo de dispositivos de contención a lo largo de su trazado, "que la idea de unas fronteras abiertas nos parece hoy en día increíblemente rara, por no decir terriblemente peligrosa, aun cuando las cruzamos con una frecuencia cada vez mayor" (Harvey 2017: 302) ${ }^{16}$. Sin embargo, lo que en

\footnotetext{
15 Sin duda, con este tipo de propuesta se daría un paso más en la degradación del espíritu utópico, una considerable contracción o deflación de las expectativas: "El objetivo ya no es conseguir una sociedad mejor [], sino mejorar la propia situación individual dentro de esa sociedad tan esencial y definitivamente incorregible" (Bauman 2017: 21).

16 Probablemente falta la suficiente perspectiva histórica para comprender cómo el control permanente de las fronteras y aún más su fortificación representa una ruptura con hábitos seculares (Sager 2020). Conocer la historia de las fronteras y de sus funciones contribuye a cuestionar la imagen hoy naturalizada de los controles migratorios como algo necesario para garantizar la seguridad nacional. Aunque hoy pueda parecer extraño, considerar las migraciones como una amenaza de la que hay que protegerse no fue siempre la visión dominante. Hubo
} 
realidad es reciente y, por ende, raro en términos históricos, es el régimen fronterizo actualmente en alza (aunque su implantación dista de ser universal) ${ }^{17}$ y más novedoso aún es el grado en que muchos inmigrantes son vistos como un problema de seguridad y tratados como si fueran criminales.

Sin duda, una política migratoria de puertas abiertas configuraría un estado de cosas contrapuesto al que últimamente se acostumbra a ver, pero ello no significa que sea una propuesta menos viable que otras formuladas a lo largo de la historia para responder a conflictos reales irresueltos y que en su momento podrían parecer ilusorias y hoy forman parte de nuestra realidad social. Sin ingenuidad alguna, cabe preguntarse si de hecho no resulta mucho más utópica la opción opuesta propugnada desde posiciones autodesignadas como realistas (Pécoud y Guchteneire 2006: 82). Y con esta pregunta no se alude exclusivamente al cierre completo de fronteras y puertos, a la «inmigración cero» tan anhelada por algunos populismos de corte chovinista, sino también a la simple pretensión de mantener los flujos migratorios bajo el implacable control de los Estados. Ante las reiteradas inconsistencias que genera la gestión política de estos flujos, la apertura de fronteras se presenta como una opción razonable digna de ser tomada en consideración. En todo caso, es tan realista o más que el pensamiento hegemónico sobre la materia. De ahí que ya vaya siendo hora de que se abra en serio el debate público sobre una política de apertura y si el balance costes/beneficios — políticos, económicos y, sobre todo, humanosque provoca dicha política es más favorable o menos que el balance derivado de una política de rigurosa contención de los flujos migratorios.

La propuesta de un mundo con fronteras abiertas constituye, en gran medida, un espejo invertido de las inquietantes políticas migratorias que los Estados ponen en marcha a diario. En contraste con esa realidad, es un proyecto utópico de pequeño formato que simplemente pretende señalar una vía para evitar o al menos minimizar los grandes y constantes males generados por la obsesión de control en la que está atrapada la mayoría de los Estados contemporáneos: se trataría, en definitiva, de una utopía concentrada fundamentalmente en la prevención de los daños provocados por ese irracional afán controlador dirigido a excluir a los más desfavorecidos de la Tierra. Aunque no se lograra alcanzar la meta propuesta, del mismo hecho de plantear esta posibilidad se extraería ya un considerable rendimiento práctico, tal como sostiene Joseph Carens (2013: 296), el filósofo que, sin duda, más ha aportado para lograr hacer de esta propuesta una idea intelectualmente respetable: "El ob-

tiempos, y no muy remotos, en los que las personas que migraban apenas encontraban trabas, eran bienvenidas e incluso alentadas (Livi Bacci 2012).

${ }^{17}$ A nivel continental, abundan los ejemplos de fronteras abiertas: es el caso de los Estados de la Unión Europea, o entre ciertos Estados de Australasia, así como en Sudamérica. 
jetivo del argumento de las fronteras abiertas es desafiar la complacencia, hacernos conscientes de cómo las prácticas democráticas rutinarias en inmigración niegan la libertad y ayudan a mantener la desigualdad injusta".

La propuesta tiene mucho de desafío del pensamiento hegemónico, con un enorme potencial para cuestionar la justificación de políticas que ahora se dan por sentadas. Pero no puede quedarse en eso sólo. Si no se quiere incurrir en un mero ejercicio de diversión intelectual, sino desplegar una reflexión alentada por una pretensión práctica y por el afán de transformar la realidad social, se requiere ser cuidadoso en su diseño. En un deslinde previo, es preciso distinguirla nítidamente de la idea de un "mundo sin fronteras» (borderless world), que no cumple con las mínimas condiciones de viabilidad en el actual contexto geopolítico. Mucho más matizada y accesible y, por ende, comparativamente más realista, es la idea "fronteras abiertas» (open borders), que no cuestiona la vigente división del mundo en Estados soberanos. No obstante, esta idea requiere algunos ajustes para poder ser implementada, de los que ahora tan sólo se nombrarán dos. En primer lugar, la apertura de las fronteras no sería indiscriminada. Las fronteras no desaparecerían, pero se modificarían tanto las funciones regulativas atribuidas hasta ahora a tales dispositivos como el modo de gestionarlas. Las fronteras persistirían en cuanto demarcaciones territoriales de entidades estatales independientes y, por tanto, de ámbitos jurisdiccionales diferenciados. En segundo lugar, no estarían descartadas las restricciones coyunturales al tránsito fronterizo en caso de acontecimientos excepcionales. Las autoridades estatales estarían facultadas para cerrar temporalmente las fronteras - y, por tanto, restaurar los controles fronterizos- si concurren determinadas circunstancias, entre las que caben señalar, por ejemplo, que se haya declarado una pandemia o que, en el interior del propio país, se registren catástrofes naturales, conflictos bélicos o situaciones de riesgo inminente de ataque terrorista. En todo caso, esas circunstancias deberían estar convenientemente tasadas para impedir la discrecionalidad gubernamental y evitar que la posibilidad de imponer restricciones dé pie a limitaciones desproporcionadas de la libertad de movimiento, libertad que, en todo caso, tendría que constituir la regla general, de modo que aquello que es meramente pensado como excepcionalidad no se convierta en normalidad.

Aun con estas precisiones, no se trata de una propuesta acomodaticia. Más bien, por el contrario, cuestiona ese dictum supuestamente realista y expresión máxima del pensamiento único de que frente al statu quo «no hay alternativa» (There is no alternative, el famoso eslogan político atribuido a Margaret Thatcher). El hecho de que se suela dar por supuesto que no existe una alternativa factible al actual estado de cosas, por más que la mayoría de las personas lo considere injusto, habría que achacarlo en el plano teórico al predominio de una comprensión fetichizante de las 
condiciones sociales (Honneth 2017: 22), algo que, en un plano más práctico, se traduce en unas claras tendencias al conformismo.

Las fronteras abiertas son hoy en día poco más que una idea programática que puede servir de guía en esa navegación en la que estamos embarcados toda la humanidad, una ambiciosa idea ante la que cabe expresar un prudente escepticismo en vista de la situación real del mundo. Si no se le atribuye virtudes milagrosas y se evita sugerir que su implementación traería consigo la superación de todos los males e injusticias del mundo, tiene, con todo, el valor impagable de nutrir el debate en la esfera pública mundial y contrarrestar tendencias autárquicas claramente hegemónicas.

\section{Reflexiones finales}

Los AVANCES TECNOLÓGICOS, el soporte material de los procesos de globalización, han difuminado algunas fronteras, pero han contribuido también a potenciar otras, incluso a crearlas (Foucher 2016). Como se ha tratado de mostrar a lo largo de este artículo, que estas últimas derivas se hayan potenciado en el período que llevamos del tercer milenio no significa, sin embargo, que estos cambios sean precisamente lo más idóneos para la conducción de los acontecimientos actuales (Graziano 2017).

Si lo que se pretende evitar es el asentamiento de inmigrantes, la política de cierre de fronteras y la inversión de ingentes cantidades para controlarlas tienen efectos contraproducentes. Si las fronteras se fortifican y se aumenta el control para el libre tránsito, aumenta notablemente el riesgo y el coste de cruzarla. Ante ello, los migrantes, de manera muy racional, reducen el número de veces que la transitan. Las políticas restrictivas no logran que disminuya la presión migratoria, pero dificulta y encarece la empresa, de modo que quien lo consigue intentará rentabilizar su esforzada inversión y quedarse sin fecha de vuelta. Aunque sea en condiciones de precariedad, los migrantes prefieren mantenerse en el país en el que han logrado asentarse y no emprender otra vez desde cero su penosa trayectoria. Por el contrario, es un hecho contrastado que "las fronteras abiertas fomentan el retorno de los inmigrantes a su país de origen” (Bregman 2017: 208).

Ni las nuevas fronteras ni el fortalecimiento de las viejas pueden resolver ninguno de los desafíos de nuestro tiempo. Lejos de ser una solución, el cierre de fronteras — una expresión desesperada de soberanía, como señalaba Han (2020)— es tan sólo el inicio de una espiral de nuevos problemas. Por un lado, la xenofobia, el aislacionismo y la desconfianza se encuentran detrás de la construcción de muros, cuya presencia a su vez retroalimentan y potencian dichas actitudes. Por otro, la 
intensificación de los controles fronterizos y la multiplicación de obstáculos físicos provocan un incremento considerable de la inmigración clandestina, que produce a su vez una reacción desproporcionada por parte de los Estados receptores en el manejo punitivo de la inmigración económica en general. Este modo de gestionar el control de las fronteras degrada además de manera muy severa los estándares mínimos de derechos y garantías incluso en las democracias más consolidadas. En realidad, no son sino "una respuesta vieja frente a nuevos desafíos, una anomalía legal, el penúltimo estertor de una idea del mundo que se resiste a morir" (Naranjo Noble 2020: 60).

Si el cierre de fronteras se ha revelado no sólo lesivo para la dignidad humana, sino también ineficaz, ¿por qué continuar con las fronteras bloqueadas para el tránsito de los migrantes internacionales? En la actualidad, el mero hecho de plantear la posibilidad de reconocer la libre circulación de personas - y, con ella, la paulatina configuración de un mundo con fronteras abiertas - suele ser considerado un desafío directo a una sacrosanta facultad atribuida tradicionalmente a dichas entidades soberanas: la de controlar sus fronteras territoriales y reservarse el derecho de admisión. El pensamiento presuntamente realista, que es actualmente el hegemónico, sigue troquelado por una presunción ideológica que entiende como agresión todo aquello que desnaturalice lo que nunca debió naturalizarse. De ahí la recia resistencia ante cualquier cuestionamiento de la división del planeta por medio de fronteras. Sin embargo, pensar hoy en modificar el statu quo no es sólo una opción, es una urgencia. 


\section{REFERENCIAS BibLIOGRÁficas}

Abizadeh, Arash. 2008. "Democratic Theory and Border Coercion". Political Theory 61: 37-65.

Andersson, Ruben. 2014. Illegality, Inc. Oakland: University of California Press.

Balibar, Étienne. 2005. Violencias, identidades y civilidad, Barcelona: Gedisa.

Bauman, Zygmunt. 2016. Extraños llamando a la puerta. Barcelona: Paidós.

Bauman, Zygmunt. 2017. Retrotopía. Barcelona: Paidós.

Boudou, Benjamin. 2018. Le dilemme des frontières. París: Éditions EHESS.

Bregman, Rutger. 2017. Utopía para realistas. Barcelona: Salamandra.

Brezger, Jan. 2018. Internationale Freizügigkeit als Menschenrecht. Fráncfort: Campus.

Brubaker, Rogers. 2017. "Between nationalism and civilizationism: the European populist moment in comparative perspective". Ethnic and Racial Studies 40 (8): 1191-1226.

Brown, Wendy. Estados vallados, soberanía en declive. Barcelona: Herder.

Campillo, Antonio. 2019. Un lugar en el mundo. Madrid: Catarata.

Cortina, Adela. 2017. Aporofobia, el rechazo al pobre. Barcelona: Paidós.

De Genova, Nicholas P. "Migrant «illegality» and deportability in everyday life". Annual Review of Anthropology 31: 419-447.

FitzGerald, David Scott. 2019. Refuge beyond Reach. How Rich Democracies Repel Asylum Seekers. Oxford: Oxford U.P.

Foucher, Michel. 2012. L’obsession des frontières. París: Terrin.

Foucher, Michel. 2016. Le retour des frontières. París: CNRS.

Frye, David. 2019. Muros. La civilización a través de sus fronteras. Madrid: Turner.

Graziano, Manlio. 2017. Frontiere, Bolonia: Il Mulino.

Harvey, David. 2017. El cosmopolitismo y las geografias de la libertad. Madrid: Akal.

Habermas, Jürgen. 1998. Facticidad y validez. Madrid: Trotta.

Habermas, Jürgen. 2000. La constelación posnacional. Barcelona: Paidós. 
Han, Byung-Chul. 2020. "La emergencia viral y el mundo de mañana”. En: $E l$ País, 22 marzo de 2020. https://elpais.com/ideas/2020-03-21/la-emergencia-viral-y-el-mundo-de-manana-byung-chul-han-el-filosofo-surcoreano-que-piensadesde-berlin.html

Honneth, Axel. 2017. La idea del socialismo. Buenos Aires / Madrid: Katz.

IOM. 2019. Migration Data Portal. URL $=$ https://migrationdataportal.or$\mathrm{g} /$ ?i=stock_abs_\&t=2017

Krastev, Ivan. 2017. "Un futuro para las mayorías”. En S. Alba et al. (Eds.), El gran retroceso. Barcelona: Seix Barral, 151-170.

Lakoff, George. 2007. No pienses en un elefante. Madrid: Editorial Complutense.

Latour, Bruno. 2019. Dónde aterrizar. Cómo orientarse en politica. Madrid: Taurus.

Livi Bacci, Massimo. 2012. Breve historia de las migraciones. Madrid: Alianza.

Mezzadra, Sandro y Brett Neilson. 2017. La frontera como método. Madrid: Traficantes de Sueños.

Milanovic, Branko. 2017. Desigualdad mundial. México: FCE.

Miller, David. 2005. "Immigration: The Case For Limits". En: A. I. Cohen and C. H. Wellman (eds), Contemporary Debates in Applied Ethics. Oxford: Blackwe11, 193-206.

Miller, David. 2016. Strangers in Our Midst. Cambridge, MA: Harvard U.P.

Naranjo Noble, José. 2020. "El amargo trance del retorno forzoso". Claves de razón práctica 270: 52-60.

Oberman, Kieran. 2011. "Immigration, Global Poverty and the Right to Stay". Political Studies 59 (2): 253-268.

Organización de las Naciones Unidas. 2018. Pacto Mundial para una Migración Segura, Ordenada y Regular. Recuperado de http://www.un.org/es/conf/migration/global-compact-for-safe-orderly-regular-migration.shtml

Pécoud, Antoine y Paul de Guchteneire. 2006. "International Migration, Border Controls and Human Rights". Journal of Borderlands Studies Volume 21 (1): 69-86.

Penchaszadeh, Ana Paula y Sferco, Senda Inés. 2019. "Solidaridad y Fraternidad. Una nueva clave ético-política para las migraciones". REMHU - Revista Interdisciplinar da Mobilidade Humana 27 (55): 149-164.

Risse, Mathias. 2012. On Global Justice. Princeton: Princeton U.P.

Rodier, Claire. 2013. El negocio de la xenofobia. Madrid: Clave Intelectual. 
Rodríguez Ortiz, Roxana. 2020. "Los estudios sobre fronteras internacionales desde una perspectiva comparativa”. En: E. Coraza de los Santos y Ma S. Lastra (eds), Miradas a las migraciones, las fronteras y los exilios. Buenos Aires: CLACSO, 23-41.

Sager, Alex. 2020. Against Borders: Why the World Needs Free Movement of People, Lanham, MD: Rowman \& Littlefield.

Sampedro, José Luis. 1991. Desde la frontera. Madrid: Real Academia Española. Sassen, Saskia. 2001. ¿Perdiendo el control? La soberanía en la era de la globalización, Barcelona: Bellaterra.

Sassen, Saskia. 2017. "La pérdida masiva de habitat". Iglesia viva 270: 11-38.

Savater, Fernando. 2000. "Prólogo". En: Tahar Ben Jelloun, Papá, ¿qué es el racismo? Madrid: Alfaguara, 7-10.

Shklar, Judith. 2010. Los rostros de la injusticia. Barcelona: Herder.

Taguieff, Pierre-André. 2012. Le nouveau national-populisme. París: CNRS.

Tertrais, Bruno y Delphine Papin. 2018. Atlas de las fronteras. Madrid: Cátedra.

Vallet, Élisabeth. 2019. "Prosigue el amurallamiento del mundo, aunque sea ineficaz, costoso y letal". En: Migraciones. Reflexiones civicas, 17 septiembre. Recuperado de http://www.madrimasd.org/blogs/migraciones/2019/09/17/132793

Vallet, Élisabeth y Charles-Ph. David. 2012. "Introduction. Du retour des murs frontaliers en relations internationales". Etudes internationales 43 (1): 5-25.

Velasco, Juan Carlos. 2016. El azar de las fronteras. México: FCE.

Velasco, Juan Carlos. 2020. "Hacia una visión cosmopolita de las fronteras". Revista Internacional de Sociología (REIS) 78(2): e153.

Walzer, Michael. 1993. Las esferas de la justicia. México: FCE.

Weber, Leanne, ed. 2015. Rethinking Border Control for a Globalizing World. Londres / Nueva York: Routledge.

Wind, Marlene. 2019. La tribalización de Europa. Barcelona: Espasa/Planeta.

Ypi, Lea. 2008. "Justice in Migration: A Closed Borders Utopia?". The Journal of Political Philosophy 16(4): 391-418.

Zamora, José Antonio. 2019. "Nacionalismo autoritário e «religião da vida cotidiana”". Caminhos 17: 30-53.

DOI: http://dx.doi.org/10.15366/bp.2020.23.001

Bajo Palabra. II Época. No23. Pgs: 23-48 
